\title{
Accuracy and Characteristics of Offshore Wind Speeds Simulated by WRF
}

\author{
Susumu Shimada and Teruo Ohsawa \\ Graduate School of Maritime Sciences, Kobe University, Kobe, Japan
}

\begin{abstract}
This paper discusses the accuracy and characteristics of offshore wind speeds simulated by the Weather Research and Forecasting (WRF) model. Firstly, the accuracy of the simulated wind speed is examined using in-situ measurements from the Shirahama offshore research platform for the whole year of 2005. It is found that the WRF surface wind speed has an annual bias of $15.3 \%$, which is much larger than the National Centers for Environmental Prediction Final Analysis data (NCEP FNL) used as input. Secondly, the possibility of accuracy improvement of the simulated wind speed is discussed in terms of the decomposition of RMSE and the estimation error of wind energy density. As a result, it is shown that reducing the large positive bias is a key to increase the accuracy of the WRF wind speed. Without the large bias, the error in the estimation of annual mean wind energy density drastically decreases from $47 \%$ to $4 \%$. Finally, the accuracy of wind speeds above the surface layer is examined using wind profiler measurements from Mihama. It is found that the WRF wind speed has large positive biases not only near the sea surface but also in the lower PBL. Thus, the large positive biases are speculated to be mainly due to inaccuracy of the PBL scheme in WRF.
\end{abstract}

\section{Introduction}

Recently methodologies for the offshore wind resource assessment independent of in-situ measurements have been enterprisingly researched in some Northern European countries as their national projects, to reduce technical and financial costs of development of facilities for offshore wind power generation. In these projects, the use of a mesoscale model is expected to be one of the useful methodologies, and some related studies including not only validation of the model but also development of suitable physical schemes for offshore wind simulation are already under way (Jimenez et al. 2007; Suselj and Sood 2010).

In Japan as well, a government-led feasibility study on offshore wind power generation started in 2008 , and the country has just taken the first step toward full-fledged installation of offshore wind power generation in the future. For the installation it is crucially important to assess offshore wind resources based on a reliable methodology. However, due to the lack of offshore in-situ measurements that can be used for validation, there are still many unknowns about the reliability of mesoscale models for offshore wind simulation. In particular, their performances for Japanese coastal waters, surrounded by complex terrains and influenced by prevailing dynamical and thermo-dynamical circulations, have hardly ever been discussed, except a few case studies (e.g., Ohsawa et al. 2005).

In this point of view, the offshore research platform of Shirahama Oceanographic Observatory, located in Tanabe Bay in Wakayama Prefecture is one of the handful, precious stations that have observed offshore winds for a long time. The authors have thus utilized this offshore research platform as their research base since 2007 (Shimada et al. 2009). In this paper, the in-situ measurements from the Shirahama research platform are used to investigate the reliability of a mesoscale model for offshore wind simulation. The Weather Research and Forecasting (WRF) model is used as the mesoscale model in this study.

Corresponding author: Susumu Shimada, Kobe University, 5-1-1 Fukaeminami, Higashi-nada, Kobe 658-0022, Japan. E-mail: 061w801w@stu. kobe-u.ac.jp. (C2011, the Meteorological Society of Japan.
Details of the simulation and validation method are described in Section 2. In Section 3, one-year simulation is performed with WRF and the accuracy is examined using the in-situ measurements from the Shirahama offshore research platform. The errors are analyzed through the decomposition of Root-Mean-SquareError (RMSE) and the estimation of wind energy density, and then the possibility of improvement of the accuracy is discussed. Moreover, accuracy of the simulated wind speeds above the surface layer is examined using the wind profiler measurements in order to clarify the cause of errors in the simulated surface wind. Finally results of this study are summarized in Section 4.

\section{Data and methods}

\subsection{Configuration of WRF}

The Weather Research and Forecasting (WRF) model version 3.0 (Skamarock et al. 2008) is used in this study. WRF is a fully compressible, non-hydrostatic model with a large number of physics options regarding cumulus parameterization, cloud microphysics, radiation, PBL parameterization and land surface model. The model also includes multiple nesting and four-dimensional data assimilation (FDDA) options using gird nudging, which enable us to hindcast meteorological conditions realistically.

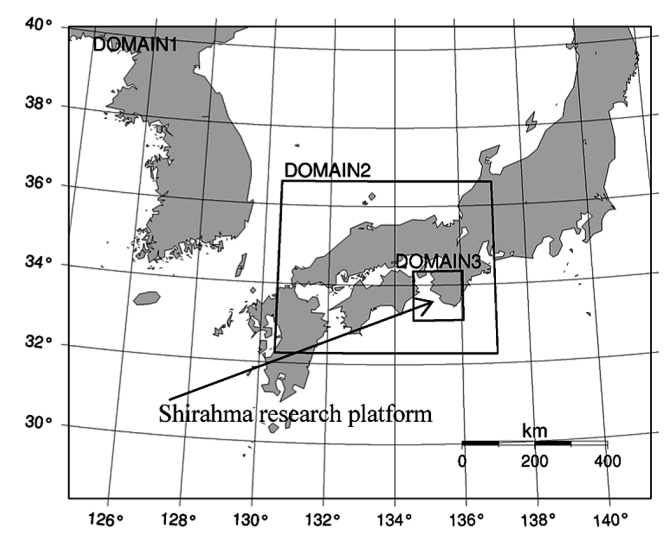

Fig. 1. Domains used in the simulation.

Table 1. Configuration of WRF.

\begin{tabular}{ll}
\hline Period & Start: 00:00 UTC 1 Jan 2005 \\
& End: 24:00 UTC 31 Dec 2005 \\
\hline Input data & NCEP FNL Analysis $\left(6\right.$-houlry, $\left.1^{\circ} \times 1^{\circ}\right)$ \\
& NGSST-O (daily, $\left.0.05^{\circ} \times 0.05^{\circ}\right)$ \\
\hline Nesting & 2-way nesting \\
\hline Domain & Domain 1: $18 \mathrm{~km}(86 \times 75$ grids) \\
& Domain 2: $6 \mathrm{~km}(100 \times 82$ grids) \\
& Domain 3: $2 \mathrm{~km}(70 \times 70$ grids $)$ \\
\hline Vertical layer & 28 levels (suface to 50 hPa) \\
\hline Physics options & Dudhia short wave radiation \\
& RRTM long wave radiation \\
& WSM3 cloud micropysics \\
& Kain-Fritsch 2 cumulus parameterization \\
& Five-layer soil model \\
& MYJ PBL parameterization \\
\hline FDDA option & Enable excluding domains 2 and 3 PBL \\
\hline
\end{tabular}




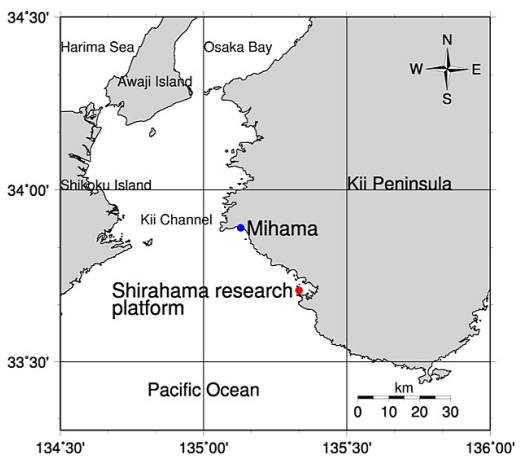

Fig. 2. Location of the Shirahama offshore research platform and the Mihama wind profiler station.
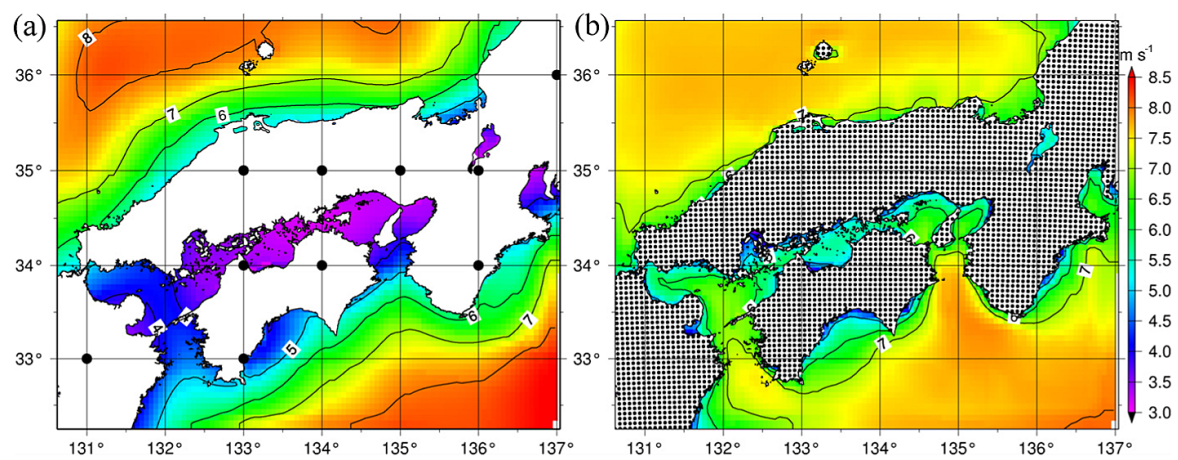

Fig. 3. Annual mean wind speeds obtained from (a) NCEP FNL $\left(1^{\circ} \times 1^{\circ}\right)$ and (b) WRF $(6 \mathrm{~km} \times 6 \mathrm{~km})$ at the $23 \mathrm{~m}$ height in the year 2005. Black dots show land grids represented in each data, respectively.
The WRF simulation is performed for the whole year of 2005 with the 2-way nesting option for three domains gradually focusing on the Shirahama area. The domains used in this simulation are shown in Fig. 1 and model configuration is summarized in Table 1. Horizontal resolutions of the three domains 1,2 and 3 are $18 \mathrm{~km}, 6 \mathrm{~km}$ and $2 \mathrm{~km}$ respectively. Vertically 28 levels are configured between the surface and the $50 \mathrm{hPa}$ pressure level, and the vertical grid-size decreases towards the surface. Heights of the lowest three levels are approximately $27 \mathrm{~m}, 94 \mathrm{~m}$ and $185 \mathrm{~m}$, respectively. The National Centers for Environmental Prediction Final Analysis $\left(1^{\circ} \times 1^{\circ}, 6\right.$-hourly) data (NCEP FNL), which has 24 levels from surface to $10 \mathrm{hPa}$ is used for the four-dimensional data assimilation as well as initial and lateral boundary conditions. The detail of NCEP FNL is available at http://dss.ucar.edu/datasets/ ds083.2. For the lower boundary condition over water, the New Generation Sea Surface Temperature for Open Ocean (NGSST-O, $0.05^{\circ} \times 0.05^{\circ}$, daily) provided by Tohoku University (Sakaida et al. 2009) is used. The two horizontal wind components, temperature and specific humidity simulated by WRF are nudged toward NCEP FNL with the FDDA option, and the FDDA option is applied to the whole domain 1, the domains 2 and 3 excluding PBLs in this simulation. Here, the PBL height in the simulation is diagnostically calculated from the vertical gradient of turbulence kinetic energy. Primary physics options selected in this simulation are also shown in Table 1.

\subsection{In-situ data used for evaluation of simulated wind speed}

Accuracy of the surface wind speeds simulated by WRF is examined using in-situ measurements from the offshore research platform of Shirahama Oceanographic Observatory, Disaster Prevention Research Institute, Kyoto University. The research platform is located at the mouth of Tanabe Bay $\left(33^{\circ} 42^{\prime} 32^{\prime \prime} \mathrm{N}\right.$, $\left.135^{\circ} 19^{\prime} 58^{\prime \prime} \mathrm{E}\right), 2 \mathrm{~km}$ away from the nearest coastline. The research platform is $23 \mathrm{~m}$ in height, standing on the seabed at a depth of $10 \mathrm{~m}$. Wind speed is measured by a propeller anemometer on the top of the research platform and the measurements are used for the validation of WRF-simulated wind speeds. Additional details of the research platform are given by Shimada et al. (2009). For the simulated wind speeds above the surface layer, the accuracy is evaluated based on wind profiler measurements from the Japan Meteorological Agency (JMA) observation station, Mihama, located approximately $40 \mathrm{~km}$ away from the Shirahama offshore research platform. Further descriptions of the JMA wind profiler is given by Ishihara et al. (2006). The location of the Shirahama offshore research platform and the Mihama wind profiler station are shown in Fig. 2.

\section{Results and discussion}

\subsection{Accuracy of simulated surface wind speed}

Hereafter the accuracy and characteristics of wind speed simulated by WRF are examined from a comparison with mea- surements, and in order to show the advantage of the use of a mesoscale model for the offshore wind simulation over coarser resolution datasets, in parallel the same analysis is carried out with NCEP FNL, which is used as input for the WRF simulation.

Figure 3 shows annual mean wind speed fields obtained from the NCEP FNL and WRF wind speeds for the year 2005, and land grids represented in each data are also shown in Fig. 3. It is found that since NCEP FNL has a much coarser land-ocean distribution $\left(1^{\circ} \times 1^{\circ}\right)$ compared to WRF $(6 \mathrm{~km} \times 6 \mathrm{~km})$, the offshore wind speed field from NCEP FNL does not well correspond to indented coastlines. In contrast, the WRF wind speed field obviously exhibits more realistic wind fields including influences from complex topography and indented coastlines. Moreover it seems that the NCEP FNL wind speeds are higher than the WRF wind speeds in open oceans.

In order to examine the accuracy of the NCEP FNL and WRF wind speeds, bias, RMSE and correlation coefficient are calculated using the in-situ measurements from the Shirahama research platform. The nearest grid point values from the research platform in NCEP FNL and WRF in domain 3 are used for the validation. Since the NCEP FNL grid spacing is too coarse to specify the nearest gird, the NCEP FNL data is firstly interpolated onto the same grids with WRF $(2 \mathrm{~km} \times 2 \mathrm{~km})$ using the WRF preprocessing system. Next the NCEP FNL wind speed is extrapolated to the anemometer height of $23 \mathrm{~m}$ using the log profile as-
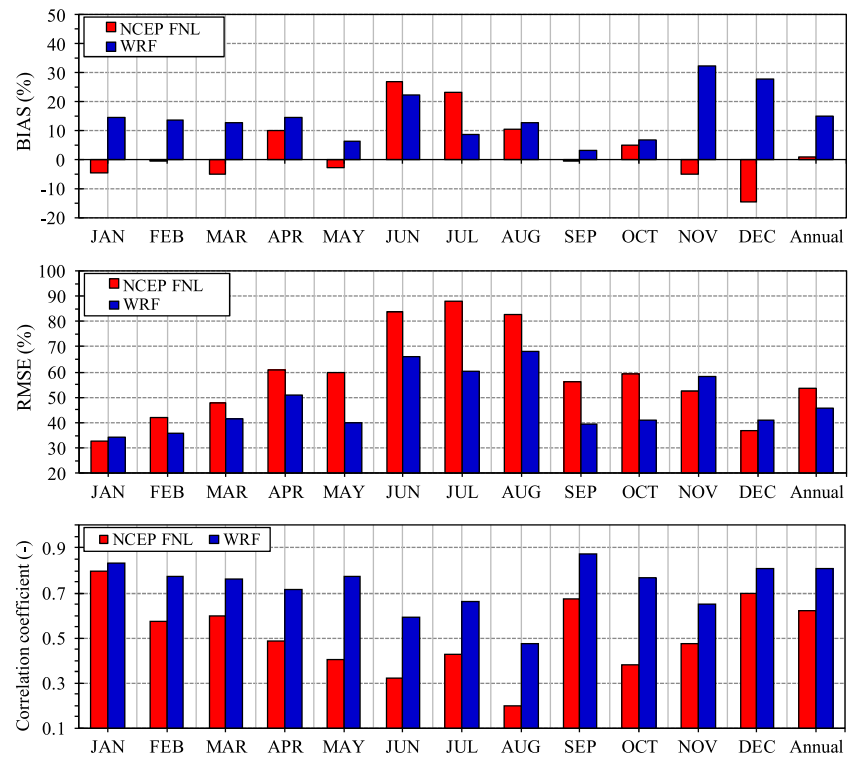

Fig. 4. Monthly bias, RMSE and correlation coefficient at Shirahama for NCEP FNL and WRF. The bias and RMSE are expressed as relative values to the monthly mean wind speed. 
sumed roughness length of $0.2 \mathrm{~mm}$. Since wind speed at the $10 \mathrm{~m}$ height is diagnostically calculated using the Monin-Obukhov similarity theory in the WRF simulation, the WRF wind speed is interpolated into the $23 \mathrm{~m}$ height using upper and lower grid values as shown in Eq. (1).

$$
U_{23}=\frac{U_{27}-U_{10}}{\ln \left(z_{27}\right)-\ln \left(z_{10}\right)} \times\left(\ln \left(z_{23}\right)-\ln \left(z_{10}\right)\right)+U_{10} .
$$

Also in order to adjust temporal resolution between the NCEP FNL and WRF wind speeds, only 6-hourly data is used for the validation.

Figure 4 shows the monthly biases, RMSEs and correlation coefficients of the NCEP FNL and WRF wind speeds against the measurements at Shirahama. Here, since the bias and RMSE generally tend to increase with the mean wind speed, relative values to the measured mean wind speed are mainly used in this study. The NCEP FNL and WRF wind speeds have an annual bias of 0.7 and $15.3 \%$, respectively. Compared to the NCEP FNL, the WRF wind speed is found to have a much larger positive bias. In Fig. 4 it is moreover found that the WRF wind speed has a notable positive bias every month. In contrast, annual correlation coefficients are 0.62 and 0.81 for NECP FNL and WRF, respectively, and the WRF wind speed has much higher values than NCEP FNL. This implies that WRF succeeds in reproducing local effects such as land-sea breezes by taking into account more realistic land-ocean distribution in the model than NCEP FNL, and this leads to the high correlation coefficients. As for RMSE, NCEP FNL and WRF have a similar value (53.8 and $46.0 \%$, respectively) in terms of the annual mean.

Besides, hourly mean wind speeds obtained from measurements (black squares), NCEP FNL (red triangles) and WRF (blue circles) at the Shirahama research platform in the year 2005 are shown in Fig. 5. It is found that the hourly mean wind speed from measurements has an obvious diurnal cycle. While the wind speed during nighttime shows an almost constant value of approximately $5 \mathrm{~m} \mathrm{~s}^{-1}$, it begins to increase at 9 LST, and then it reaches maximum at 14 LST. After that the wind speed gradually decreases as time passes. On the other hand, the hourly mean wind speed from WRF is found to well capture such a diurnal cycle as found in measurements compared to NCEP FNL. However, the amplitude of the diurnal cycle in the WRF wind speed is slightly smaller than measurements. This is speculated to be attributable to what the SST dataset used in the WRF simulation does not take into account diurnal variations.

\subsection{Evaluation and improvement of wind speed errors}

Three statistics (bias, RMSE and correlation coefficient) are examined in the previous section, but it is noted that these three values are not independent to each other. According to Lange and Focken (2006), RMSE can be decomposed into bias (BIAS), standard deviation bias (SDBIAS) and dispersion (DISP). The decomposition of RMSE is given by

$$
\mathrm{RMSE}^{2}=\mathrm{BIAS}^{2}+\mathrm{SDBIAS}^{2}+\mathrm{DISP}^{2} \text {. }
$$

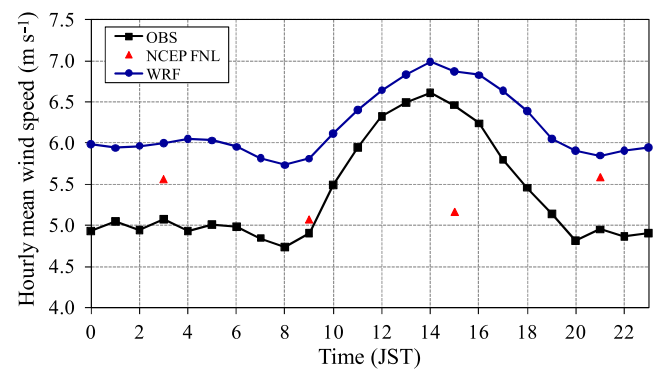

Fig. 5. Hourly mean wind speeds obtained from measurements (black), NCEP FNL (red) and WRF (blue) at the $23 \mathrm{~m}$ height at the Shirahama research platform in the year 2005 .
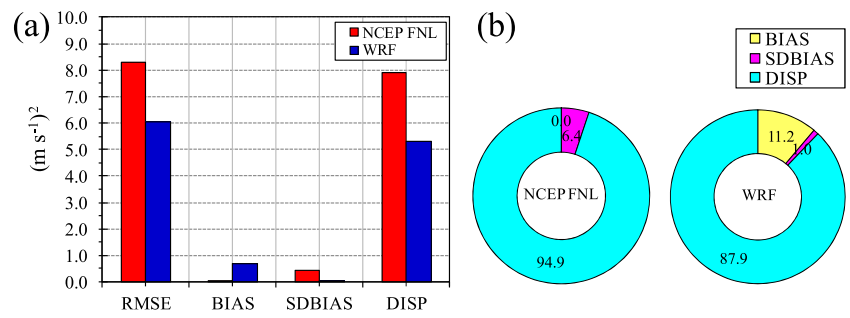

Fig. 6. (a) Decomposition of RMSE in the NCEP FNL and WRF wind speeds at Shirahama, and (b) contribution ratio (\%) of BIAS, SDBIAS and DISP to RMSE.

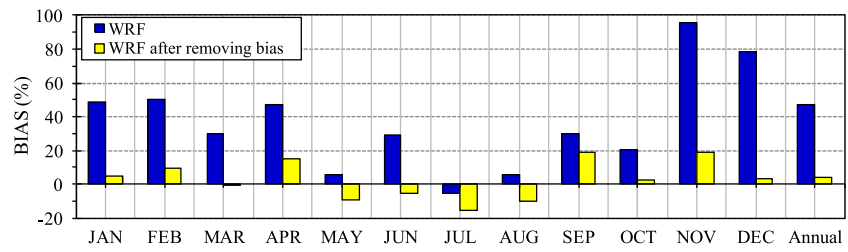

Fig. 7. Monthly and annual biases in wind energy densities at Shirahama calculated from WRF (blue bars) and from WRF after removing monthly biases of wind speed (yellow bars).

Figure 6a shows the square values of RMSE, BIAS, SDBIAS and DISP calculated from the NCEP FNL and the WRF wind speeds at Shirahama, and their contribution ratios to RMSE are shown in Fig. 6b.

It is obvious in Fig. 6 that a large part of RMSE comes from DISP in the NCEP FNL and WRF wind speeds. DISP is a function of correlation coefficient, and it generally tends to decrease as correlation coefficient increases. In fact, the order of DISPs shown in Fig. 6 is completely opposite to that of annual correlation coefficients shown in Fig. 4. Moreover, Fig. 6a indicates that the WRF wind speeds have significantly smaller DISP than the NCEP FNL. This difference between WRF and NCEP FNL seems to be attributable to the improvement of reproducibility of local effects due to the much finer land-ocean distribution in the WRF simulation compared to NCEP FNL. While WRF exhibits smaller values in SDBIAS as well as DISP in Fig. 6a, it is only BIAS that is larger in WRF than in NCEP FNL. After all, the results from Figs. 4 and 6 imply that improvement of the large positive bias is a key to increase the accuracy of the WRF wind speed at the research platform.

This point of view can be also confirmed in terms of wind energy density $(1 / 2 \times$ air density $\times$ a cube of wind speed $)$, which is a more suitable parameter for wind resource assessment. Figure 7 compares two kinds of errors in the mean wind energy density at Shirahama; One is calculated from the raw WRF wind speeds and another is calculated from the WRF wind speeds but for removing the monthly biases. As found in Fig. 7, the wind energy density from the raw wind speed has an error of $47 \%$ for the annual mean. In contrast, the wind energy density after removing the wind speed bias has the error of $4 \%$. That is, the estimation error in wind energy density considerably decreases by removing the annual bias of wind speed. In other words, reducing the bias, rather than reducing RMSE and increasing correlation coefficient, is crucially important in terms of wind resource assessment.

\subsection{Accuracy of wind speeds above surface layer}

Consequently, "where does the large positive bias of the WRF simulations come from?" is a question that arises here. In order to investigate a cause of the bias, in this study, the wind profiler measurements at Mihama, described in Section 2.2, are used to see if WRF has such a large positive bias in and above the PBL as well as the surface layer. Figure 8 is the result, showing the annual bias, RMSE and correlation coefficient of the NCEP FNL and WRF wind speeds at heights from 400 to $9,000 \mathrm{~m}$. It is found that 

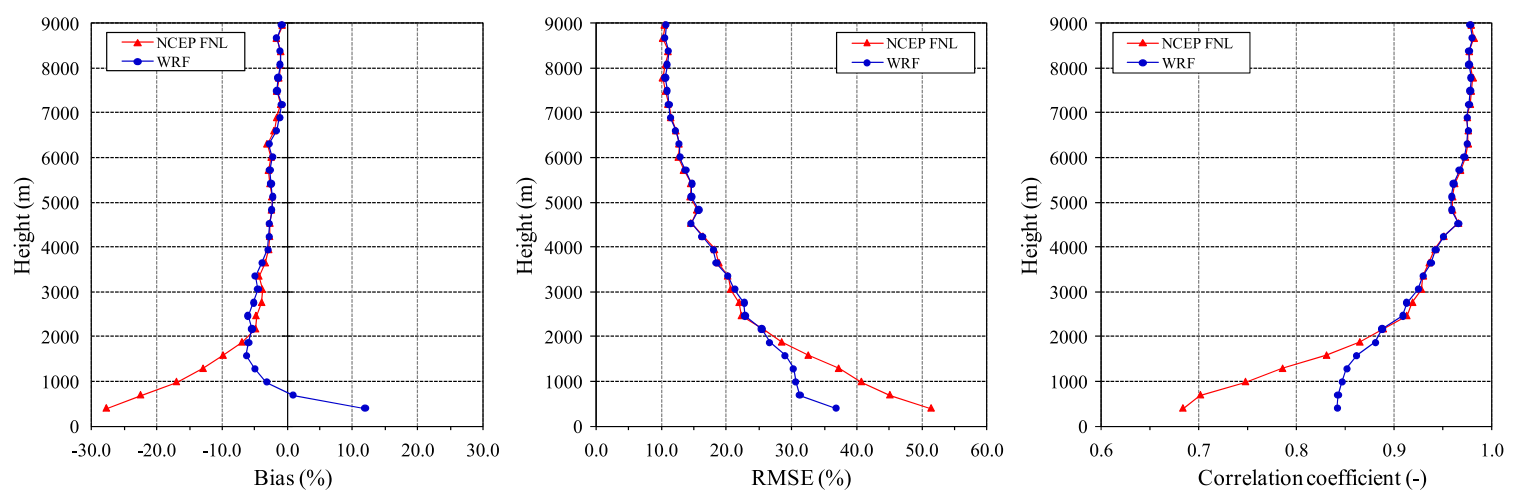

Fig. 8. Annual bias, RMSE and correlation coefficient of the NCEP FNL and WRF wind speeds at heights from 400 to $9,000 \mathrm{~m}$.

the accuracy of the NCEP FNL and WRF wind speeds gradually become worse toward the surface. The differences between NCEP FNL and WRF become pronounced under a height of $1,900 \mathrm{~m}$, because in the WRF simulations the grid nudging is applied for only above the PBL. The height of 1,900 $\mathrm{m}$ corresponds to the average height of the top of the PBL simulated in the model.

As shown in Fig. 8, at the top of the PBL, NCEP FNL has an annual bias of $-6.9 \%$, RMSE of $28.5 \%$ and correlation coefficient of 0.87 , while WRF has an annual bias of $-6.0 \%$, RMSE of $26.6 \%$ and correlation coefficient of 0.88 . In the PBL, these statistics for WRF are all better than those for NCEP FNL, indicating that the accuracy of wind speeds in the PBL is greatly improved by using WRF, which has more realistic land-ocean distribution near coastlines. But, it is noteworthy that the WRF wind speeds become to have a positive bias as the surface approaches, despite the negative bias at the top of the PBL. The bias drastically increases under the height of $1,000 \mathrm{~m}$, and this tendency seems to lead to the large positive bias in the surface layer found at Shirahama. In other words, the large positive bias is not limited in the surface layer but prevails in the lower PBL.

In our recent research, it is shown that the sea surface temperature (SST) from NGSST-O, used for a lower boundary condition in the WRF simulation, tends to have a positive bias (higher temperatures) in the area around Shirahama. This overestimation of SST is then found to cause a positive bias in the simulated surface wind speed by making stronger unstable conditions. We thus made more accurate SST dataset based on the MODIS satellite data to remove the positive bias of SST and applied it to the WRF simulation. This attempt, however, could not completely remove the large positive bias of wind speed, and there still remained an annual bias of $7.5 \%$.

Up to the present, the main cause of the large positive biases of wind found in the surface layer and the lower PBL has not been identified, unfortunately. Thus, in order to improve the accuracy of offshore wind speed in the lower PBL as well as surface wind speed, further studies are needed especially for re-examining of the PBL scheme implemented in the WRF model.

\section{Conclusion}

In this paper, in order to investigate the reliability of a mesoscale model for offshore wind simulation, the accuracy and characteristics of offshore wind speeds simulated by the WRF model are examined using in-situ measurements from the Shirahama offshore research platform and wind profiler measurements from the adjacent JMA Mihama station. The main conclusions are summarized as follows.

1. Compared with in-situ measurements at Shirahama, the WRF wind speeds have an annual bias of $15.3 \%$, RMSE of $46.0 \%$ and correlation coefficient of 0.81 .

2. Decomposition of RMSE in the WRF wind speeds indicates that improvement of the large positive bias is a key to increase the accuracy of the WRF wind speed. In fact, if the bias is removed, the accuracy of wind energy density estimation is greatly improved (from $47 \%$ down to $4 \%$ ).

3. Comparison with the wind profiler measurements shows that the bias in the WRF wind speed is negative at the top of the PBL, but it becomes positive under a height of 1,000 m, drastically increasing toward the surface. That is, the positive bias is not limited in the surface layer but prevails in the lower PBL.

4. Although the positive bias is found to be partly due to overestimation of SST, the main cause has not been identified in this paper. Further studies are needed especially for re-examining of the PBL scheme in WRF to improve the accuracy of offshore wind speed estimation.

\section{Acknowledgements}

The authors are grateful to the chief editor, Dr. Saito and anonymous reviewers for their constructive comments. This study was supported by a Grant-in-Aid for Japan Society for the Promotion of Sciences Fellows 216911 from the Ministry of Education, Science, Sport and Culture, Japan. The authors are grateful to Prof. T. Hayashi, Prof. Y. Muto, Kyoto University, assistant Prof. T. Suzuki and technical officer T. Kubo for their efforts in routine observation at the Shirahama Oceanographic Observatory.

\section{References}

Ishihara, M., Y. Kato, T. Abo, K. Kobayashi, and Y. Izumikawa, 2006: Characteristics and performance of the operational wind profiler network of the Japan Meteorological Agency. J. Meteor. Soc. Japan, 84, 1085-1096.

Jimenez, B., F. Durante, B. Lange, T. Kreutzer, and J. Tambke, 2007: Offshore wind resource assessment with WAsP and MM5: comparative study for the German Bight. Wind Energy, 10, 121-134.

Lange, M., and U. Focken, 2006: Physical approach to short-term wind power prediction. Springer, 1-208.

Ohsawa, T., A. Hashimoto, S. Shimada, J. Yoshino, T. D. Paus, D. Heinemann, and B. Lange, 2007: Evaluation of offshore wind simulations with MM5 in the Japanese and Danish coastal waters. Proc. of EWEC 2007, Milan, Italy.

Sakaida, F., H. Kawamura, S. Takahashi, T. Shimada, Y. Kawai, K. Hosoda, and L. Guan, 2009: Research and development of the New Generation Sea Surface Temperature for Open Ocean (NGSST-O) product and its demonstration operation. J. Oceanogr., 65, 859-870.

Shimada, S., T. Ohsawa, S. Serizawa, and I. Yoneda, 2009: Characteristics of offshore winds at Shirahama Oceanographic Observatory. Proc. of ISOPE 2009, 424-428.

Skamarock, W. C., J. B. Klemp, J. Dudhia, D. O. Gill, D. M. Barker, W. Wang, and J. G. Powers, 2008: A description of the advanced research WRF version 3. Tech. Note, TN-475+STR, 1-96.

Suselj, K., and A. Sood, 2010: Improving the Mellor-Yamada-Janjic Parameterization for wind conditions in the marine planetary boundary layer. Bound. Layer Meteor., 136, 301-324.

Manuscript received 28 September 2010, accepted 6 January 2011

SOLA: http://www.jstage.jst.go.jp/browse/solal 